\title{
MERCURY CONTAMINATION AND POPULATION-LEVEL RESPONSES IN CHIRONOMIDS: CAN ALLOZYME POLYMORPHISM INDICATE EXPOSURE?
}

\author{
Lee Ann Woodward, $* \dagger$ Margaret Mulvey $\ddagger$ and Michael C. Newman $\$$ \\ $\dagger$ University of California-Davis, CA, and Savannah River Ecology Laboratory, Aiken, South Carolina 29802, USA. \\ $\ddagger$ University of Georgia, Savannah River Ecology Laboratory, Aiken, South Carolina 29802, USA
}

(Received 11 August 1995; Accepted 16 January 1996)

\begin{abstract}
Allozyme frequencies of Chironomus plumosus were determined along a gradient of sediment mercury concentrations in a contaminated lake. We examined whether allozyme frequencies could be used to distinguish populations along the gradient or between contaminated and reference sites. No significant correlations were found between allozyme frequencies and contamination, but an overall deficit of heterozygotes (in nine of 13 loci examined) was found at all sites sampled. While toxicant stress could be the cause, a more parsimonious explanation would be sampling over a patchy population structure leading to a heterozygote deficiency (i.e., Wahlund effect). Examination of allozyme frequencies along a transect indicated that the observed deficiency of heterozygote genotypes was due to sampling across some fine-scale substructuring of the populations. The findings of these studies lend a note of caution regarding the use of allozymes to infer population effects of contaminants or their potential use as biomarkers. Studies must define population structure, naturally occurring variation within and among populations, and relevant ecological factors in conjunction with the presence of xenobiotics and their concentrations.
\end{abstract}

Keywords-Allozyme Mercury Chironomids Wahlund effect Population genetics

\section{INTRODUCTION}

Individuals, populations, and species can differ widely in their tolerance to xenobiotics. While a lack of tolerance will exclude species populations from a polluted site, the ability of some populations to survive in polluted environments has focused attention on contaminants as selective agents and factors contributing to differential tolerance. Xenobiotics could affect survivorship or reproductive success, thus lowering the Darwinian fitness (viability and fecundity) of individuals that are sensitive to the toxicant. Tolerant individuals then predominate in the population that persists in a polluted environment. If a mechanism involved in xenobiotic tolerance is readily assayed, then it may potentially be used to monitor exposure [1]. Although the evaluation of population-level responses to contaminants is basic to the understanding of the longterm effects of sublethal contamination prevalent in many habitats, few such assays are available [2].

Electrophoretically determined genetic data are widely used to study population processes, e.g., population structure, selection, and regulation. The potential to use allozymes as indicators of selection has led to numerous studies of allozyme variation and toxicant exposure. Nevo and coworkers [3-10] found differential survivorship among allozyme genotypes for several marine species between contaminated and reference conditions in both laboratory and field situations. Guttman and coworkers [11-13] also found correlations for several enzyme-determining loci with toxicant exposure. Studies by Mitton and Koehn [14] on mummichog minnows (Fundulus heteroclitus) and Smith et al. [15] on largemouth bass (Micropterus salmoides) found that allozyme frequencies differed significantly between populations inhabiting artificially heated waters relative to those of unheated waters.

These studies indicate that some aquatic populations can respond to contaminant exposure or environmental alteration and

\footnotetext{
* To whom correspondence may be addressed.
}

this may be accompanied by changes in allozyme frequencies. How useful is this alteration of population allozyme genotypes as a tool in the assessment of risk to exposed populations? To date, most evidence has been correlative between contamination and allozyme frequencies, and therefore we cannot unambiguously deduce cause and effect. Correlations do not necessarily signify cause and effect. It is necessary to evaluate processes that might lead to a relationship between contaminant and allozyme frequencies, then we can evaluate their utility as markers.

In this study we examined allozyme frequencies as a potential diagnostic of population response to chronic exposure to mercury. Allozyme genotypes were assessed in midge larvae (Chironomus plumosus) living in mercury-contaminated lake sediments. Sediments of Clear Lake (Lake County, CA, USA) contain a gradient of mercury concentration originating from the century-old Sulphur Bank Mercury Mine (Fig. 1) [16]. If allozyme genotype frequencies were related to exposure to xenobiotics, we would predict a cline in allele frequencies congruent with the mercury gradient. Alternatively, overall genetic variability might differ along the gradient or between contaminated and reference sites. Specifically, the hypotheses examined were that there is no loss of allelic variability in relation to contaminant exposure, there is no change in allozyme frequencies along the mercury gradient, and there are no differences in allozyme frequencies between contaminated and reference sites. Additionally, allozyme frequencies were examined at a sampling scale of $1-\mathrm{m}$ quadrats along a $15-\mathrm{m}$ transect to test the hypothesis that there was not sufficient population structure to account for the observed allelic variability.

\section{METHODS}

\section{Gradient survey}

The nonbiting midge $C$. plumosus spends the greatest portion of its life as an immature larva in lake sediments. Once in early 


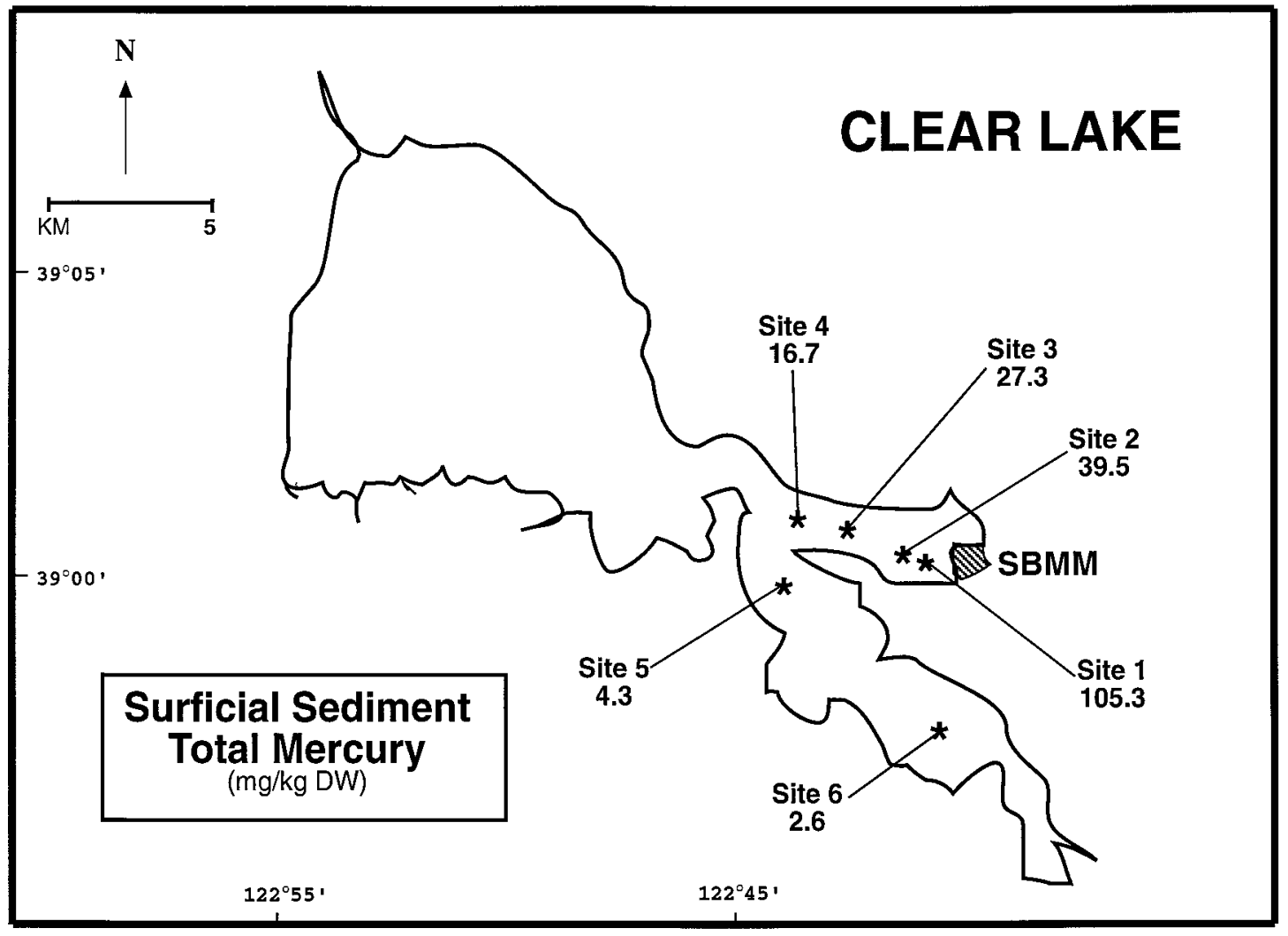

Fig. 1. Location of gradient survey sites. Six sites situated along the sediment mercury gradient were sampled for chironomids (Chironomus plumosus). Sediment mercury concentrations are due to runoff and tailings from the Sulphur Bank Mercury Mine (SBMM).

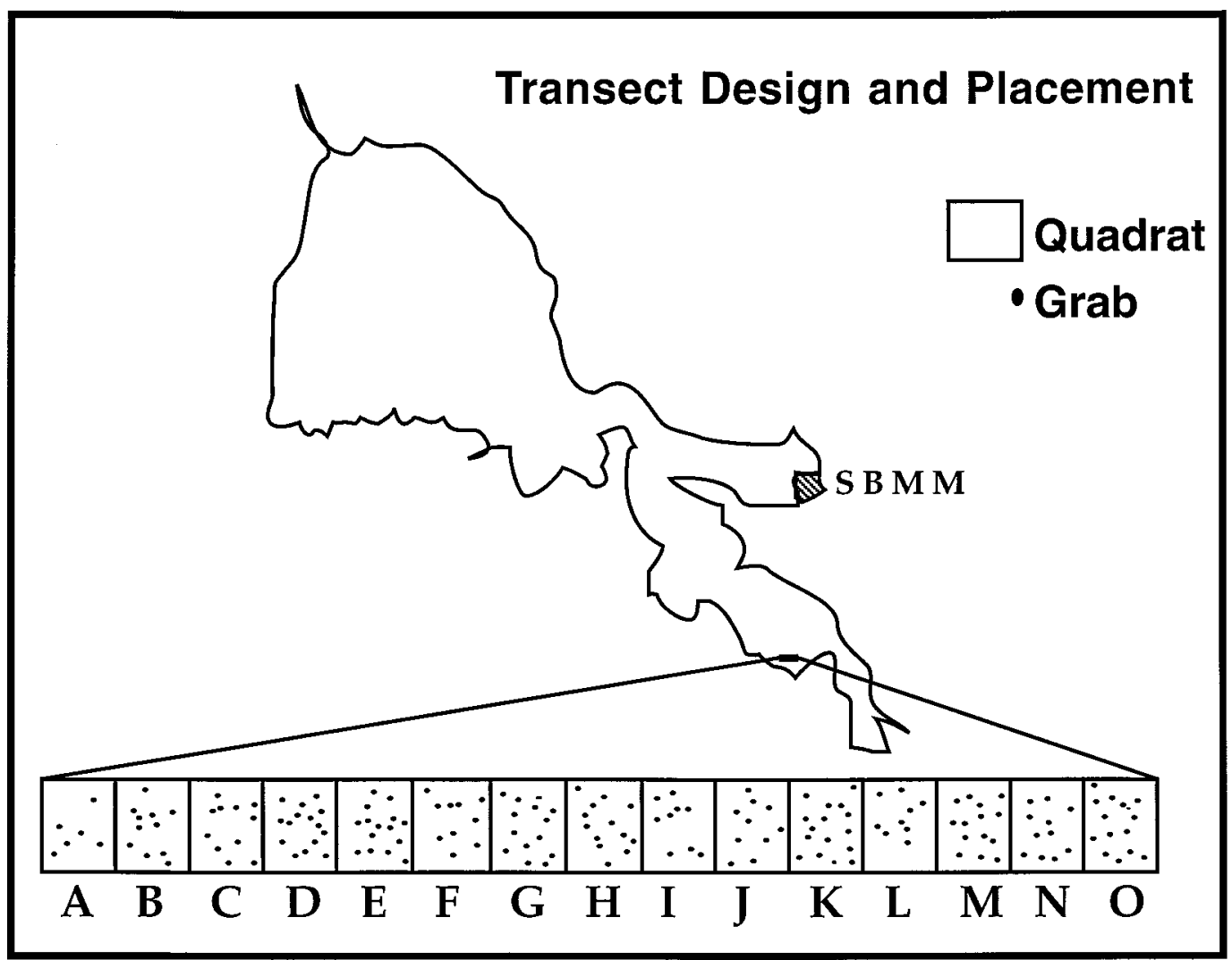

Fig. 2. Location and schematic of the transect study. Fifteen 1-m quadrats were sampled for allozyme spatial variability in Chironomus plumosus. 
Table 1. Distribution of alleles in midges taken from the six sites of the gradient study (Clear Lake, CA, USA, Fig. 1)

\begin{tabular}{|c|c|c|c|c|c|c|c|c|c|c|c|c|}
\hline \multirow[b]{2}{*}{ Allele } & \multicolumn{12}{|c|}{ Locus $^{\mathrm{a}}$} \\
\hline & gl & $\operatorname{lgg}$ & Est & Aat & $\mathrm{Hk}$ & Mpi & $\mathrm{Me}$ & Pgm & Ada & Mdh & Icd-1 & Icd-2 \\
\hline \multicolumn{13}{|l|}{ Site 1} \\
\hline $\mathrm{D}$ & 0.044 & 0.011 & & 0.227 & & 0.044 & 0.011 & 0.200 & & 0.179 & 0.011 & 0.011 \\
\hline $\mathrm{E}$ & 0.944 & 0.556 & 0.591 & 0.705 & 0.933 & 0.956 & 0.956 & 0.800 & 0.693 & 0.810 & 0.978 & 0.989 \\
\hline $\mathrm{F}$ & 0.011 & 0.411 & 0.409 & 0.068 & 0.067 & & 0.033 & & 0.307 & 0.012 & 0.011 & \\
\hline $\mathrm{G}$ & & 0.022 & & & & & & & & & & \\
\hline $\mathrm{HWE}^{\mathrm{a}}$ & $*$ & $*$ & & & & & $*$ & $*$ & & & & \\
\hline$D^{\mathrm{b}}$ & -0.371 & -0.191 & -0.154 & -0.238 & 0.071 & 0.047 & -0.481 & -0.306 & -0.092 & 0.218 & 0.017 & 0.011 \\
\hline \multicolumn{13}{|l|}{ Site 2} \\
\hline $\mathrm{C}$ & & & & & & 0.017 & & & & 0.018 & & \\
\hline $\mathrm{D}$ & 0.008 & 0.022 & & 0.161 & & 0.025 & & 0.133 & & 0.027 & & \\
\hline $\mathrm{E}$ & 0.983 & 0.533 & 0.567 & 0.831 & 0.967 & 0.942 & 1.000 & 0.867 & 0.717 & 0.938 & 0.992 & 1.000 \\
\hline $\mathrm{F}$ & & 0.411 & 0.433 & & 0.033 & 0.017 & & & 0.283 & 0.018 & 0.008 & \\
\hline $\mathrm{G}$ & 0.008 & 0.033 & & 0.008 & & & & & & & & \\
\hline HWE & & & & & & $*$ & & & & $*$ & & \\
\hline$D$ & 0.013 & -0.021 & -0.186 & -0.046 & 0.034 & -0.026 & & -0.135 & -0.015 & -0.553 & 0.008 & \\
\hline \multicolumn{13}{|l|}{ Site 3} \\
\hline $\mathrm{D}$ & 0.016 & & & 0.250 & & 0.011 & 0.016 & 0.164 & 0.008 & 0.070 & & 0.016 \\
\hline $\mathrm{E}$ & 0.977 & 0.592 & 0.711 & 0.731 & 0.898 & 0.989 & 0.984 & 0.836 & 0.695 & 0.930 & 1.000 & 0.977 \\
\hline $\mathrm{F}$ & & 0.398 & 0.289 & 0.010 & 0.102 & & & & 0.297 & & & 0.008 \\
\hline $\mathrm{G}$ & 0.008 & 0.010 & & 0.010 & & & & & & & & \\
\hline HWE & & & & & & & $*$ & & $*$ & & & $*$ \\
\hline$D$ & 0.019 & 0.080 & -0.050 & -0.237 & 0.113 & 0.011 & -1.000 & -0.163 & -0.453 & 0.075 & & -0.660 \\
\hline \multicolumn{13}{|l|}{ Site 4} \\
\hline $\mathrm{C}$ & & & & 0.020 & & & & & & & & \\
\hline $\mathrm{D}$ & 0.058 & 0.010 & & 0.290 & 0.009 & & & 0.221 & & 0.144 & & 0.009 \\
\hline $\mathrm{E}$ & 0.923 & 0.529 & 0.491 & 0.600 & 0.887 & 0.978 & 1.000 & 0.750 & 0.794 & 0.846 & 1.000 & 0.925 \\
\hline $\mathrm{F}$ & 0.019 & 0.461 & 0.509 & 0.060 & 0.104 & 0.022 & & 0.019 & 0.196 & & & 0.066 \\
\hline $\mathrm{G}$ & & & & 0.030 & & & & 0.010 & 0.010 & 0.010 & & \\
\hline HWE & & & & $*$ & & & & $*$ & & & & \\
\hline$D$ & -0.067 & -0.188 & -0.245 & -0.093 & 0.117 & 0.022 & & 0.040 & 0.008 & 0.169 & & -0.196 \\
\hline \multicolumn{13}{|l|}{ Site 5} \\
\hline $\mathrm{C}$ & & & & 0.026 & & & & 0.008 & & 0.008 & & \\
\hline $\mathrm{D}$ & 0.051 & & & 0.289 & & 0.017 & & 0.178 & & 0.100 & 0.025 & 0.033 \\
\hline $\mathrm{E}$ & 0.949 & 0.592 & 0.675 & 0.614 & 0.908 & 0.983 & 1.000 & 0.805 & 0.767 & 0.892 & 0.975 & 0.958 \\
\hline $\mathrm{F}$ & & 0.408 & 0.325 & 0.053 & 0.092 & & & & 0.233 & & & 0.008 \\
\hline $\mathrm{G}$ & & & & 0.018 & & & & 0.008 & & & & \\
\hline HWE & & & $*$ & $*$ & & & & & & $*$ & $*$ & $*$ \\
\hline$D$ & 0.054 & -0.207 & -0.278 & -0.246 & 0.101 & 0.017 & & -0.100 & 0.014 & 0.026 & -0.658 & -0.378 \\
\hline \multicolumn{13}{|l|}{ Site 6} \\
\hline $\mathrm{C}$ & & & & 0.008 & & & & & & & & \\
\hline $\mathrm{D}$ & 0.040 & 0.008 & & 0.274 & & 0.008 & & 0.129 & & 0.040 & 0.008 & \\
\hline $\mathrm{E}$ & 0.960 & 0.540 & 0.613 & 0.677 & 0.855 & 0.960 & 1.000 & 0.871 & 0.734 & 0.960 & 0.984 & 0.976 \\
\hline $\mathrm{F}$ & & 0.444 & 0.387 & 0.016 & 0.145 & 0.032 & & & 0.266 & & 0.008 & 0.024 \\
\hline $\mathrm{G}$ & & 0.008 & & 0.024 & & & & & & & & \\
\hline HWE & & & * & & & * & & & & & & \\
\hline$D$ & 0.042 & -0.243 & -0.456 & -0.098 & 0.170 & -0.379 & & 0.005 & -0.050 & 0.042 & 0.012 & 0.025 \\
\hline
\end{tabular}

${ }^{\mathrm{a}}$ Aat $=$ Aspartate aminotransferase; Ada = adenosine deaminase $;$ Est = esterase $; \mathrm{gl}=$ glycylleucine peptidase; Hk = hexokinase; Icd- 1 and $-2=$ isocitrate dehydrogenase; lgg = leucylglycylglycine peptidase; Mdh = malate dehydrogenase; Me = malic enzyme; Mpi = mannose-6-phosphate isomerase; Pgm = phosphoglucomutase.

${ }^{\mathrm{b}} \mathrm{HWE}=$ Probability associated with $\chi^{2}$ test of fit to Hardy-Weinberg expectations; $*$ significant at $\alpha=0.05 . D=H_{\text {obs }}-H_{\text {exp }}$, where $D$ is a measure of fixation and $H$ is the proportion of heterozygous genotypes.

spring and once in late summer (at Clear Lake), the larvae pupate and emerge in clouds of winged adults that swarm over the area of the lake from which they emerged. Over the next few days the adults mate, lay their eggs (each egg mass contains several hundred eggs), and die. The larvae hatch and sink to the sediment, where they remain as detrital feeders living in tubes constructed in the sediment. They quickly go through four instars, then remain in the final instar until emergence approx. 3 to 9 months later [17]. Due to the intimate sediment contact during their long larval phase, any differential survival due to mercury in the sediment would likely occur during this phase.
A minimum of 40 midges was sieved $(0.5 \mathrm{~mm})$ from sediments collected using a 6-inch Ekman dredge at each site (Fig. 1). An average of 10 grabs was required to collect 40 individuals per site. Midges were held alive in jars of lake water on ice until return to the laboratory, where they were placed individually in labeled microcentrifuge tubes and stored at $-70^{\circ} \mathrm{C}$. Individuals were homogenized in the tubes on ice with $0.2 \mathrm{ml}$ of grinding solution, composed of 0.01 M Tris-citrate, 0.001 M EDTA, and 0.05 mM NADP ( $\mathrm{pH} 7.0$ ). Homogenates were centrifuged, and the resulting supernatant was used for horizontal starch gel (12\% w/v) electrophoresis. The following gel buffer systems were 
used to resolve 13 presumptive genetic loci. A lithium hydroxide gel [18] was used for hexokinase (Hk; E.C. 2.7.1.1), malate dehydrogenase (Mdh; E.C. 1.1.1.37), mannose-6-phosphate isomerase (Mpi; E.C. 5.3.1.8), and aspartate aminotransferase (Aat; E.C. 2.6.1.1). A Tris-citrate gel [19] at pH 6.7 was used for adenosine deaminase (Ada; E.C. 3.5.4.4), phosphoglucomutase (Pgm; E.C. 5.4.2.2), and malic enzyme (Me; E.C. 1.1.1.40). Poulik discontinuous gel [18] was used for the peptidases using glycylleucine and leucylglycylglycine as substrates (gl and lgg; E.C. 3.4.11.-). Tris-citrate-EDTA [19] was used for esterase ( $\alpha$-naphthyl propinate substrate, or Est; E.C. 3.1.1.-), isocitrate dehydrogenase (Icd-1 and -2; E.C. 1.1.1.42), and alcohol dehydrogenase (Adh; E.C. 1.1.1.1). Allozyme mobilities were determined relative to the most common allozyme for each locus, which was arbitrarily designated "E." Thereby, the designation Icd-1 EE indicated an individual homozygous for the common Icd-1 allele, whereas Icd-1 EF indicated a heterozygous individual. The Icd- $2 \mathrm{G}$ allele was treated as a null allele because of the occurrence of a two-banded phenotype of equal intensity. Typically, Icd has a dimeric structure, and heterozygotes have a three-banded phenotype.

Each polymorphic locus was tested for fit of genotype frequencies to those expected under Hardy-Weinberg equilibrium using a $\chi^{2}$ statistic. Wright's $F$ statistics [20] were used for the analysis of population structure. $F$ statistics are equivalent to correlation coefficients that measure the correlation between uniting gametes under various sampling schemes. $F_{\text {it }}$ is the correlation of uniting gametes relative to gametes drawn at random from the entire population. $F_{\text {is }}$ is the correlation of uniting gametes relative to gametes drawn at random from within a subpopulation (averaged over subpopulations), and $F_{\text {st }}$ is the correlation of gametes within subpopulations relative to gametes drawn at random from the entire population [21]. Contingency $\chi^{2}$ statistics were used to compare differences in allele frequencies within and among sites and between contaminated and reference arms of the lake. A measure of fixation, Selander's $D$ $[22,23]$, was calculated for each locus, where $D$ equals the proportion of heterozygous genotypes observed minus the proportion of heterozygous genotypes expected for a population in Hardy-Weinberg equilibrium.

The SAS [24] general linear models (GLMs), one-way analysis of variance with a Šidák option was used to analyze allele distribution, and sediment concentration data, to test for differences among the six sites and between the contaminated and reference arms of the lake (experimentwise $\alpha=0.05$ ).

\section{Transect study}

In this part of the study an investigation was conducted to determine the population structure of $C$. plumosus at a smaller scale in order to describe the "within-site" population structure. We estimated that the grabs for each site in the gradient survey came randomly from an area of roughly $10 \mathrm{~m}^{2}$. Therefore, to reduce the scale of the investigation, the "site" was reduced to a 1-m quadrat. A transect of 15 adjoining quadrats covered the length of the estimated original sample area. A minimum of 40 individuals per quadrat was collected for the estimation of population allelic frequency.

The transect was placed in shallow water $(5 \mathrm{~m})$ to permit accurate retrieval of sediments from each of the quadrats. A rope marked off in $151-\mathrm{m}$ increments was stretched across a bay in the reference arm (Fig. 2). Midges were collected as in the gradient survey and identified for quadrat. Laboratory procedures and analytical methods were the same as those used in
Table 2. Summary of $F$ statistics at all loci. Allozymes assayed from chironomids sampled from the six sites in the gradient survey (Fig. 1)

\begin{tabular}{lrrr}
\hline Locus $^{\mathrm{a}}$ & $F_{\text {is }}{ }^{\mathrm{b}}$ & $F_{\text {it }}{ }^{\mathrm{c}}$ & $F_{\text {st }}{ }^{\mathrm{d}}$ \\
\hline $\mathrm{gl}$ & 0.078 & 0.087 & 0.010 \\
lgg & 0.128 & 0.130 & 0.003 \\
Est & 0.231 & 0.248 & 0.022 \\
Aat & 0.165 & 0.181 & 0.019 \\
Hk & -0.116 & -0.099 & 0.015 \\
Mpi & 0.142 & 0.151 & 0.011 \\
Me & 0.618 & 0.627 & 0.023 \\
Pgm & 0.107 & 0.116 & 0.010 \\
Ada & 0.107 & 0.114 & 0.007 \\
Mdh & -0.059 & -0.026 & 0.031 \\
Icd-1 & 0.219 & 0.225 & 0.009 \\
Icd-2 & 0.259 & 0.275 & 0.022 \\
Mean & 0.125 & 0.137 & 0.014 \\
\hline
\end{tabular}

${ }^{a}$ Aat $=$ Aspartate aminotransferase Ada $=$ adenosine deaminase; Est = esterase; $\mathrm{gl}=$ glycylleucine peptidase; $\mathrm{Hk}=$ hexokinase; Icd-1 and -2 = isocitrate dehydrogenase; $\operatorname{lgg}=$ leucylglycylglycine peptidase; $\mathrm{Mdh}=$ malate dehydrogenase $; \mathrm{Me}=$ malic enzyme; $\mathrm{Mpi}=$ mannose6-phosphate isomerase; $\mathrm{Pgm}=$ phosphoglucomutase.

${ }^{\mathrm{b}} F_{\text {is }}=$ Correlation between homologous alleles within individuals with reference to the local population (departure from Hardy-Weinberg expectations within local populations).

${ }^{\mathrm{c}} F_{\text {it }}=$ Correlation of alleles with reference to the total population (departure from Hardy-Weinberg expectations within the total population).

${ }^{\mathrm{d}} F_{\mathrm{st}}=$ Variance in allele frequency among populations standardized relative to maximum possible given observed mean allele frequency.

the gradient survey (see above), except only those loci with a deficiency of heterozygosity were assessed. Loci examined were Pgm, Icd-1 and -2, Ada, Est, gl, lgg, Aat, and Hk.

\section{RESULTS}

\section{Gradient survey}

Twelve of the 13 enzyme loci analyzed were polymorphic. Small deviations from Hardy-Weinberg equilibrium were observed for a random assortment of loci at each site (Table 1), but no trends were found among sites. Allozyme frequencies were not correlated with sediment mercury concentrations. No significant trends or consistencies for any one locus were found among the six sites for the 12 polymorphic loci. No significant differences in allele frequencies were found among the six sites nor between the contaminated and reference arms of the lake. Coefficients for heterozygote deficiency or excess $(D$, Table 1$)$ showed a lack of homozygotes at all sites for all or part of nine loci (Pgm, Icd-1 and -2, Ada, Est, gl, lgg, Aat, and Hk). High $F_{\text {is }}$ values (Table 2) indicated a deficiency of heterozygote genotypes at the level of the sample site.

\section{Transect study}

Each grab averaged four individuals but ranged from zero to 15 individuals, thereby requiring six to 19 grabs per quadrat to obtain the sample size of 40 individuals. A total of 756 individuals from 178 grabs were assayed for nine enzymatic systems. Slight deviations from Hardy-Weinberg equilibrium were found for a small number of randomly assorted loci at each site (Table 3); however, no significant differences in allelic frequencies were found among the 15 quadrats. An excess of homozygotes was found within the transect $\left(F_{\text {it, }}\right.$, Table 4$)$ and within quadrats $\left(F_{\text {is }}\right.$, Table 4$)$. 
Table 3. Allozyme frequencies in midges taken from the 15 quadrats of the transect study (Clear Lake, CA, USA, Fig. 1)

\begin{tabular}{|c|c|c|c|c|c|c|c|c|c|}
\hline \multirow[b]{2}{*}{ Allele } & \multicolumn{9}{|c|}{ Locus $^{\mathrm{a}}$} \\
\hline & Pgm & Ada & $\mathrm{gl}$ & $\operatorname{lgg}$ & Aat & Icd-1 & Icd-2 & Est & $\mathrm{Hk}$ \\
\hline \multicolumn{10}{|c|}{ Quadrat A } \\
\hline B & & & & & 0.020 & & & & \\
\hline $\mathrm{C}$ & 0.250 & 0.020 & & 0.029 & 0.214 & 0.010 & 0.029 & 0.010 & \\
\hline $\begin{array}{l}\mathrm{D} \\
\mathrm{E}\end{array}$ & 0.750 & 0.775 & 0.990 & 0.569 & 0.724 & 0.980 & 0.961 & 0.657 & 0.946 \\
\hline $\mathrm{F}$ & & 0.206 & & 0.392 & 0.031 & 0.010 & & 0.333 & 0.054 \\
\hline G & & & 0.010 & 0.010 & 0.010 & & & & \\
\hline $\mathrm{H}$ & & & & & & & 0.010 & & \\
\hline $\begin{array}{l}\mathrm{HWE}^{\mathrm{b}} \\
D^{\mathrm{a}}\end{array}$ & 0.120 & -0.067 & 0.010 & -0.098 & 0.145 & 0.015 & $\begin{array}{c}* \\
-0.484\end{array}$ & -0.228 & $\begin{array}{c}* \\
-0.366\end{array}$ \\
\hline \multicolumn{10}{|c|}{ Quadrat B } \\
\hline $\mathrm{C}$ & 0.303 & & 0.013 & 0.013 & 0.289 & 0.013 & & & 0.013 \\
\hline $\begin{array}{l}\mathrm{D} \\
\mathrm{E}\end{array}$ & 0.697 & 0.789 & 0.947 & 0.421 & 0.658 & 0.974 & 0.959 & 0.579 & 0.934 \\
\hline $\begin{array}{l}\mathrm{F} \\
\mathrm{G}\end{array}$ & & 0.211 & 0.039 & 0.566 & $\begin{array}{l}0.026 \\
0.026\end{array}$ & 0.013 & & 0.421 & 0.053 \\
\hline $\begin{array}{l}\mathrm{H} \\
\text { HWE }\end{array}$ & & & * & & & & 0.041 & & \\
\hline$D$ & 0.060 & -0.050 & -0.478 & -0.005 & -0.345 & 0.020 & 0.042 & -0.136 & 0.058 \\
\hline \multicolumn{10}{|c|}{ Quadrat C } \\
\hline $\begin{array}{l}\mathrm{B} \\
\mathrm{C}\end{array}$ & 0.160 & 0.049 & & & $\begin{array}{l}0.010 \\
0.214\end{array}$ & 0.010 & & 0.010 & \\
\hline $\mathrm{D}$ & 0.840 & 0.686 & 0.980 & 0.343 & 0.714 & 0.990 & 0.971 & 0.550 & 0.980 \\
\hline $\mathrm{F}$ & & 0.265 & 0.020 & 0.637 & 0.051 & & & 0.430 & 0.020 \\
\hline G & & & & 0.020 & 0.010 & & & 0.010 & \\
\hline $\begin{array}{l}\text { H } \\
\text { HWE }\end{array}$ & & $*$ & & & & & 0.029 & & \\
\hline$D$ & -0.107 & 0.031 & 0.020 & -0.217 & -0.167 & 0.010 & 0.030 & 0.054 & 0.020 \\
\hline \multicolumn{10}{|c|}{ Quadrat D } \\
\hline $\mathrm{C}$ & 0.167 & & & 0.029 & 0.231 & 0.010 & & & 0.010 \\
\hline $\begin{array}{l}\mathrm{D} \\
\mathrm{E}\end{array}$ & 0.814 & 0.567 & 1.000 & 0.452 & 0.731 & 0.981 & 0.923 & 0.578 & 0.952 \\
\hline $\begin{array}{l}\mathrm{F} \\
\mathrm{G}\end{array}$ & 0.010 & 0.433 & & 0.519 & $\begin{array}{l}0.019 \\
0.019\end{array}$ & 0.010 & 0.010 & 0.422 & 0.038 \\
\hline $\begin{array}{l}\mathrm{H} \\
\mathrm{HWF}\end{array}$ & 0.010 & $*$ & & $*$ & 8.025 & & 0.067 & & \\
\hline $\begin{array}{l}\text { HWE } \\
D\end{array}$ & -0.051 & -0.412 & & -0.085 & -0.300 & 0.015 & 0.074 & -0.075 & 0.042 \\
\hline \multicolumn{10}{|c|}{ Quadrat E } \\
\hline B & 0.012 & & & & & & & & \\
\hline $\mathrm{C}$ & 0.140 & 0.035 & & 0.012 & 0.267 & & & 0.011 & \\
\hline $\begin{array}{l}\mathrm{D} \\
\mathrm{E}\end{array}$ & 0.849 & 0.570 & 0.988 & 0.523 & 0.651 & 1.000 & 0.966 & 0.670 & 0.966 \\
\hline $\begin{array}{l}\mathrm{F} \\
\mathrm{G}\end{array}$ & & 0.395 & 0.012 & $\begin{array}{l}0.430 \\
0.035\end{array}$ & 0.081 & & 0.011 & 0.318 & 0.034 \\
\hline $\mathrm{H}$ & & & & & & & 0.023 & & \\
\hline $\begin{array}{l}\text { HWE } \\
D\end{array}$ & -0.016 & 0.213 & 0.012 & $\begin{array}{c}* \\
0.120\end{array}$ & -0.299 & & 0.027 & $\begin{array}{c}* \\
-0.443\end{array}$ & 0.035 \\
\hline \multicolumn{10}{|c|}{ Quadrat F } \\
\hline $\mathrm{C}$ & 0.133 & 0.031 & 0.010 & 0.021 & 0.250 & & & 0.021 & \\
\hline $\begin{array}{l}\mathrm{D} \\
\mathrm{E}\end{array}$ & 0.857 & 0.633 & 0.990 & 0.552 & 0.677 & 1.000 & 0.948 & 0.708 & 0.957 \\
\hline $\mathrm{F}$ & 0.010 & 0.337 & & 0.417 & 0.063 & & 0.042 & 0.271 & 0.043 \\
\hline $\begin{array}{l}\mathrm{G} \\
\mathrm{H}\end{array}$ & & & & 0.010 & 0.010 & & 0.010 & & \\
\hline $\begin{array}{l}\text { HWE } \\
D\end{array}$ & -0.011 & -0.075 & 0.010 & -0.120 & -0.167 & & 0.046 & $\begin{array}{c}* \\
-0.411\end{array}$ & 0.045 \\
\hline \multicolumn{10}{|c|}{ Quadrat G } \\
\hline B & & & & & 0.010 & & & & \\
\hline $\mathrm{C}$ & 0.160 & & 0.010 & 0.100 & 0.290 & & & 0.010 & \\
\hline $\begin{array}{l}\mathrm{D} \\
\mathrm{E}\end{array}$ & 0.840 & 0.587 & 0.990 & 0.577 & 0.670 & 0.990 & 0.981 & 0.683 & 0.961 \\
\hline $\begin{array}{l}\mathrm{F} \\
\mathrm{G}\end{array}$ & & 0.413 & & $\begin{array}{l}0.375 \\
0.038\end{array}$ & 0.030 & 0.010 & 0.010 & 0.308 & 0.039 \\
\hline $\mathrm{H}$ & & & & & & & 0.010 & & \\
\hline HWE & 0.516 & 0.227 & 0.943 & 0.951 & 0.099 & 0.944 & 0.999 & 0.075 & $* 0.001$ \\
\hline$D$ & -0.089 & -0.167 & 0.010 & 0.099 & -0.313 & 0.010 & 0.015 & -0.299 & -0.480 \\
\hline
\end{tabular}


Table 3. Continued.

\begin{tabular}{|c|c|c|c|c|c|c|c|c|c|}
\hline \multirow[b]{2}{*}{ Allele } & \multicolumn{9}{|c|}{ Locus $^{\mathrm{a}}$} \\
\hline & Pgm & Ada & gl & $\operatorname{lgg}$ & Aat & Icd-1 & Icd-2 & Est & $\mathrm{Hk}$ \\
\hline \multicolumn{10}{|c|}{ Quadrat H } \\
\hline A & & & & & & & 0.020 & & \\
\hline B & & & & & & & & & \\
\hline $\mathrm{C}$ & 0.167 & & 0.010 & & 0.265 & & & 0.010 & \\
\hline D & 0.833 & 0.676 & 0.990 & 0.559 & 0.673 & 0.980 & 0.922 & 0.529 & 0.951 \\
\hline E & & 0.010 & & & & & & & \\
\hline $\mathrm{F}$ & & 0.304 & & 0.431 & 0.051 & 0.020 & & 0.441 & 0.049 \\
\hline $\mathrm{G}$ & & 0.010 & & 0.010 & 0.010 & & & 0.020 & \\
\hline $\mathrm{H}$ & & & & & & & 0.059 & & \\
\hline HWE & & & & & & $*$ & $*$ & $*$ & \\
\hline$D$ & 0.200 & -0.433 & 0.010 & 0.016 & -0.267 & -1.000 & -0.199 & -0.252 & 0.052 \\
\hline \multicolumn{10}{|c|}{ Quadrat I } \\
\hline B & & & & & 0.031 & & & & \\
\hline $\mathrm{C}$ & 0.224 & & & & 0.240 & 0.010 & & & \\
\hline D & 0.765 & 0.602 & 0.990 & 0.635 & 0.646 & 0.990 & 0.990 & 0.480 & 0.963 \\
\hline $\begin{array}{l}\mathrm{E} \\
F\end{array}$ & 0.010 & 0.388 & 0.010 & 0.344 & 0.052 & & & 0.510 & 0.370 \\
\hline $\mathrm{G}$ & & 0.010 & & 0.021 & 0.031 & & & 0.010 & \\
\hline $\mathrm{H}$ & & & & & & & 0.010 & & \\
\hline HWE & & & & * & * & & & & \\
\hline$D$ & -0.159 & 0.006 & 0.010 & -0.259 & -0.080 & 0.010 & 0.010 & -0.159 & 0.038 \\
\hline \multicolumn{10}{|c|}{ Quadrat J } \\
\hline B & & & & & 0.010 & & & & \\
\hline $\mathrm{C}$ & 0.185 & 0.009 & 0.009 & 0.009 & 0.231 & & & 0.009 & \\
\hline D & 0.796 & 0.713 & 0.991 & 0.481 & 0.740 & 1.000 & 0.954 & 0.556 & 0.975 \\
\hline $\mathrm{E}$ & & & & & & & & & \\
\hline $\mathrm{F}$ & 0.019 & 0.259 & & 0.462 & 0.010 & & 0.009 & 0.435 & 0.025 \\
\hline $\mathrm{G}$ & & 0.019 & & 0.047 & 0.010 & & & & \\
\hline $\mathrm{H}$ & & & & & & & 0.037 & & \\
\hline HWE & & * & & & & & & & \\
\hline$D$ & 0.118 & -0.258 & 0.009 & -0.215 & -0.034 & & 0.040 & -0.336 & 0.026 \\
\hline \multicolumn{10}{|c|}{ Quadrat K } \\
\hline B & & & & & 0.009 & & & & \\
\hline $\mathrm{C}$ & 0.208 & 0.028 & & 0.085 & 0.255 & 0.019 & & & \\
\hline D & 0.792 & 0.613 & 0.981 & 0.500 & 0.623 & 0.972 & 0.953 & 0.519 & 0.947 \\
\hline E & & & & & & & & & \\
\hline $\begin{array}{l}F \\
G\end{array}$ & & 0.358 & 0.019 & $\begin{array}{l}0.396 \\
0.019\end{array}$ & 0.113 & 0.009 & 0.019 & $\begin{array}{l}0.472 \\
0.009\end{array}$ & 0.053 \\
\hline $\mathrm{H}$ & & & & & & & 0.028 & & \\
\hline HWE & & & & $*$ & & & & & \\
\hline$D$ & -0.197 & -0.199 & 0.019 & -0.130 & -0.047 & 0.023 & 0.037 & -0.072 & 0.056 \\
\hline \multicolumn{10}{|c|}{ Quadrat L } \\
\hline B & & & & & 0.010 & & & & \\
\hline $\mathrm{C}$ & 0.191 & 0.027 & & 0.027 & 0.192 & 0.019 & & & \\
\hline D & 0.800 & 0.636 & 1.000 & 0.609 & 0.760 & 0.981 & 0.972 & 0.547 & 0.991 \\
\hline E & & & & & & & & & \\
\hline $\mathrm{F}$ & 0.009 & 0.336 & & 0.345 & 0.038 & & & 0.443 & 0.009 \\
\hline G & & & & 0.018 & & & & 0.009 & \\
\hline $\mathrm{H}$ & & & & & & & 0.028 & & \\
\hline HWE & & * & & & & & & & \\
\hline$D$ & 0.124 & -0.169 & & -0.178 & -0.250 & 0.019 & 0.029 & -0.139 & 0.009 \\
\hline \multicolumn{10}{|c|}{ Quadrat M } \\
\hline B & & & & & 0.022 & & & & \\
\hline C & 0.210 & 0.510 & & 0.080 & 0.359 & & & & \\
\hline D & 0.780 & 0.776 & 0.940 & 0.450 & 0.587 & 1.000 & 0.930 & 0.470 & 0.940 \\
\hline E & & & & & & & & & \\
\hline $\mathrm{F}$ & 0.010 & 0.173 & 0.060 & 0.440 & 0.011 & & 0.010 & 0.500 & 0.060 \\
\hline G & & & & 0.030 & 0.022 & & & 0.030 & \\
\hline $\mathrm{H}$ & & & & & & & 0.060 & & \\
\hline HWE & & $*$ & $*$ & $*$ & $*$ & & & $*$ & \\
\hline$D$ & 0.151 & -0.108 & -0.645 & -0.195 & -0.214 & & 0.065 & -0.318 & 0.064 \\
\hline \multicolumn{10}{|c|}{ Quadrat N } \\
\hline C & 0.181 & 0.063 & 0.010 & & 0.304 & & & & \\
\hline D & 0.809 & 0.646 & 0.990 & 0.552 & 0.652 & 1.000 & 0.969 & 0.583 & 0.948 \\
\hline E & & & & & & & & & \\
\hline $\mathrm{F}$ & 0.011 & 0.292 & & 0.438 & 0.043 & & & 0.406 & 0.052 \\
\hline G & & & & 0.010 & & & & 0.010 & \\
\hline $\mathrm{H}$ & & & & & & & 0.031 & & \\
\hline $\begin{array}{l}\text { HWE } \\
D\end{array}$ & -0.186 & $\begin{array}{c}* \\
-0.241\end{array}$ & 0.011 & 0.117 & $\begin{array}{c}* \\
-0.457\end{array}$ & & 0.032 & -0.326 & 0.055 \\
\hline$D$ & 年 & 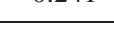 & 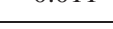 & 0.11 & 0.10 & & 0.032 & 0.520 & 0.055 \\
\hline
\end{tabular}


Table 3. Continued.

\begin{tabular}{llllllllll}
\hline & \multicolumn{7}{c}{ Locus $^{\mathrm{a}}$} \\
\cline { 2 - 10 } Allele & Pgm & Ada & gl & lgg & Aat & Icd-1 & Icd-2 & Est & Hk \\
\hline Quadrat O & & & & & & & & & \\
C & 0.194 & & & 0.020 & 0.233 & & & & \\
D & 0.806 & 0.704 & 0.990 & 0.561 & 0.722 & 1.000 & 1.000 & 0.583 & 0.981 \\
E & & & & & & & & 0.417 & 0.019 \\
F & & 0.296 & & 0.367 & 0.044 & & & $*$ & \\
G & & & 0.010 & 0.051 & & & & $*$ \\
HWE & & & & $*$ & & & & \\
$D$ & -0.151 & 0.224 & 0.010 & -0.366 & -0.210 & & & -0.400 & 0.020 \\
\hline
\end{tabular}

${ }^{a}$ Aat $=$ Aspartate aminotransferase; Ada $=$ adenosine deaminase; Est $=$ esterase; $\mathrm{gl}=$ glycylleucine peptidase; Hk = hexokinase; Icd-1 and -2 = isocitrate dehydrogenase; lgg = leucylglycylglycine peptidase; Pgm = phosphoglucomutase.

${ }^{\mathrm{b}} \mathrm{HWE}=$ Probability associated with $\chi^{2}$ test of fit to Hardy-Weinberg expectations.

* significant at $\alpha=0.05 . D=H_{\mathrm{obs}}-H_{\mathrm{exp}}$, where $D$ is a measure of fixation and $H$ is the proportion of heterozygous genotypes.

\section{DISCUSSION}

Population allozyme frequencies are not a direct measure of selection. Allozymes may be differentially inhibited by a toxicant or linked to loci that exhibit differential tolerance to toxicants. Additionally, allozyme frequencies in populations may differ between contaminated and noncontaminated environments due to bottlenecks, mutation, migration, natural selection, and/or random genetic drift. Furthermore, each of these is influenced by other local conditions besides contamination. For example; migration rates may depend on local population densities and physical barriers, and the magnitude of effects of random genetic drift depends on population size [21]. Finally, allozyme frequencies may differ due to habitat structure, climatic changes, or artifacts of sample collection. All likely possibilities must be considered.

Populations of chironomids exposed to mercury in Clear Lake showed consistent deficiency of heterozygous genotypes. An excess of homozygotes may indicate either selection against

Table 4. Summary of $F$ statistics at all loci. Allozymes assayed from chironomids sampled from the 15 quadrats in the transect survey (Fig. 2)

\begin{tabular}{lccc}
\hline Locus $^{\mathrm{a}}$ & $F_{\mathrm{is}}{ }^{\mathrm{b}}$ & $F_{\mathrm{it}}{ }^{\mathrm{c}}$ & $F_{\text {st }}{ }^{\mathrm{d}}$ \\
\hline Pgm & 0.010 & 0.020 & 0.011 \\
Ada & 0.116 & 0.138 & 0.025 \\
g1 & 0.250 & 0.264 & 0.019 \\
lgg & 0.102 & 0.124 & 0.024 \\
Aat & 0.202 & 0.210 & 0.010 \\
Icd-1 & 0.107 & 0.115 & 0.009 \\
Icd-2 & 0.021 & 0.034 & 0.014 \\
Hk & 0.024 & 0.030 & 0.006 \\
Est & 0.024 & 0.247 & 0.019 \\
Mean & 0.134 & 0.150 & 0.018 \\
\hline
\end{tabular}

${ }^{\mathrm{a}}$ Aat $=$ Aspartate aminotransferase; Ada $=$ adenosine deaminase; Est = esterase; $\mathrm{gl}=$ glycylleucine peptidase; $\mathrm{Hk}=$ hexokinase; Icd- 1 and -2 = isocitrate dehydrogenase; $\operatorname{lgg}=$ leucylglycylglycine peptidase; $\mathrm{Pgm}=$ phosphoglucomutase.

${ }^{\mathrm{b}} F_{\text {is }}=$ Correlation between homologous alleles within individuals with reference to the local population (departure from Hardy-Weinberg expectations within local populations).

${ }^{\mathrm{c}} F_{\text {it }}=$ Correlation of alleles with reference to the total population (departure from Hardy-Weinberg expectations within the total population).

${ }^{\mathrm{d}} F_{\text {st }}=$ Variance in allele frequency among populations standardized relative to maximum possible given observed mean allele frequency. heterozygotes or cryptic population structure within the sites. However, the hypothesis of selection against heterozygotes at nine loci is less probable because it requires more assumptions than that of cryptic population structure. The degree to which populations are structured can be quantified using Wright's $F$ statistics that are calculated based on differences between observed and expected heterozygosity at different scales within the total population. The positive $F_{\text {is }}$ seen for the gradient survey sites (Table 2) indicated a deficit in heterozygotes. A heterozygote deficiency may occur due to inbreeding, the Wahlund effect, and/or toxicant-induced selection. However, no correlations were seen between sediment mercury concentrations and allozyme differentiation. Further, there are no barriers to the movement of breeding adults around the lake. However, it is probable that there is a patchy pattern to the midge distribution in the lake. This may be due to localized breeding pools since the emerging adults tend to mate quickly after emergence, increasing the probability of mating with another locally emerging midge. Also, the egg masses contain several hundred eggs. If the larvae from each mass settle locally, clumping, this would also produce a patchy population structure. Thus, when sampling with an Ekman dredge, the grabs are probably being collected from many patches. Therefore, the most parsimonious explanation would be the Wahlund effect, which as seen here is thought to be due to the combining of samples taken across some patchy population structure containing different allele frequencies. If samples from two or more subpopulations with different allele frequencies are pooled together as one sample, the pooled sample population would exhibit a deficit of heterozygotes.

The transect study examined the population structure of $C$. plumosus at a smaller scale in order to describe the within-site structure. If significant genetic heterozygosity in allozyme frequency were identified, then the deficiency of heterozygous genotypes observed in the initial survey would be consistent with a notional Wahlund effect.

Wright's $F_{\text {st }}$ is a measure of genetic differences among populations [20]. Values calculated for the scale of the transect and quadrat (Table 4) indicate that little genetic differentiation is occurring among the quadrats. The implications are that there is small-scale structuring within the total site and that this is variable enough to cause the Wahlund effect when sampled at the scale used for the gradient survey.

Patterns of allozyme frequencies were not correlated with any 
notional selection in response to sediment mercury contamination. Deficits of heterozygotes found within the sites were most parsimoniously explained by the Wahlund effect caused by sampling across a patchy population structure. While speculation that observed effects in contaminated areas to xenobiotics is common, it would have been inappropriate to have interpreted our results as being due to effects of the mercury contamination.

Other studies have also found that while there may be some selection occurring due to toxicant exposure, other factors in the environment were having an equivalent or greater total effect. Diamond et al. [25] noted significant relationships between tolerance during an acute mercury exposure and allozyme genotypes at three of eight loci tested in mosquitofish (Gambusia holbrooki). However, in follow-up studies [26,27] on the same system in the same laboratory, only some of the previously found correlations between mercury exposure (time to death) and allele genotype reoccurred. The investigators suggested that the undefined population structure of the sampled population could have significant effects on test outcome. This suggestion was reinforced by Lee et al. [28], who examined the effect of population structure on the same system and found that broods of mosquitofish sharing similar genetic backgrounds but raised under slightly different environmental conditions exhibited significant differences in time to death. This strongly suggests that a nonrandom distribution of animals in a habitat (due to schooling, microhabitats, etc.) could cause population structuring and an uneven distribution of genotypes. If tolerance and allozyme genotype are not related but vary with population structure, this could account for some of the transient correlations seen during electrophoretic surveys attempting to measure population-level responses to toxicants.

The findings of these studies lend a note of caution regarding the use of allozymes to infer population effects of contaminants or their potential use as diagnostics. Future studies must consider population structure, naturally occurring variation within and among populations, and all relative ecological factors in addition to the presence of xenobiotics and their concentrations.

Acknowledgement-Financial support was obtained from the U.S. Department of Energy through the University of Georgia's Savannah River Ecology Laboratory (DE-AC09-76SR00819) and from the U.S. Environmental Protection Agency (R819658) Center for Ecological Health Research at the University of California-Davis. The electrophoretic analyses were conducted in the laboratory of Michael H. Smith. Grateful thanks go to the field crews who helped in the collection of the samples, especially Li Xiao Ping and Ruth Elbert.

\section{REFERENCES}

1. Mulvey, M. and S.A. Diamond. 1992. Genetic factors and tolerance acquisition in populations exposed to metals and metalloids. In M.C. Newman, and A.W. McIntosh, eds., Metal Ecotoxicology: Concepts and Applications. Lewis, Chelsea, MI, USA.

2. Newman, M.C. 1995. Quantitative Methods in Ecotoxicology. Lewis, Chelsea, MI, USA.

3. Nevo, E., T. Shimony and M. Libni. 1978. Pollution selection of allozyme polymorphisms in barnacles. Experientia 34:1562-1564.

4. Nevo, E., T. Pearl, A. Beiles and D. Wool. 1981. Mercury selection of allozyme variation in shrimps. Experientia 37:1152-1154.

5. Lavie, B. and E. Nevo. 1982. Heavy metal selection of phosphoglucose isomerase allozymes in marine gastropods. Mar. Biol. 71:17-22.

6. Nevo, E., B. Lavie and R. Ben-Shlomo. 1983. Selection of allelic isozyme polymorphisms in marine organisms: Pattern, theory, and application. Isozymes 10:69-92.

7. Nevo, E., R. Ben-Shlomo and B. Lavie. 1984. Mercury selection of allozymes in marine organisms: Prediction and verification in nature. Proc. Natl. Acad. Sci. U. S. A. 81:1258-1259.

8. Nevo, E., R. Noy, B. Lavie, A. Beiles and S. Muchtar. 1986. Genetic diversity and resistance to marine pollution. Biol. J. Linn. Soc. 29:139-144.

9. Lavie, B. and E. Nevo. 1988. Multilocus genetic resistance and susceptibility to mercury and cadmium pollution in the marine gastropod, Cerithium scabridum. Aquat. Toxicol. 13:291-296.

10. Ben-Shlomo, R. and E. Nevo. 1988. Isozyme polymorphism as monitoring of marine environments: The interactive effect of cadmium and mercury pollution on the shrimp, Palaemon elegans. Mar. Pollut. Bull. 19:314-317.

11. Gillespie, R.B. and S.I. Guttman. 1989. Effects of contaminants on the frequencies of allozymes in populations of the central stoneroller. Environ. Toxicol. Chem. 8:309-317.

12. Chagnon, N.L. and S.I. Guttman. 1989. Differential survivorship of allozyme genotypes in mosquitofish populations exposed to copper or cadmium. Environ. Toxicol. Chem. 8:319-326.

13. Chagnon, N.L. and S.I. Guttman. 1989. Biochemical analysis of allozyme copper and cadmium tolerance in fish using starch gel electrophoresis. Environ. Toxicol. Chem. 8:1141-1147.

14. Mitton, J.B. and R.K. Koehn. 1975. Genetic organization and adaptive response in allozymes to ecological variables in Fundulus heteroclitus. Genetics 79:97-111.

15. Smith, M.W., M.H. Smith, S.C. Scott, E.H. Liu and J.C. Jones. 1983. Rapid evolution in a post-thermal environment. Copeia 1983: 193-197.

16. Suchanek, T.H., P.J. Richerson, L.A. Woodward, D.G. Slotton, L.J. Holts and C.E.E. Woodmansee. 1993. A survey and evaluation of mercury in: sediment, water, plankton, periphyton, benthic invertebrates, and fishes within the aquatic ecosystem of Clear Lake, California. U.S. Environmental Protection Agency, San Francisco, CA.

17. Williams, D.D. and B.W. Feltmate. 1992. Aquatic Insects. C.A.B. International, Oxon, UK.

18. Selander, R.K., M.H. Smith, S.Y. Yang, W.E. Johnson and J.B. Gentry. 1971. Biochemical polymorphism and systematics in the genus Peromyscus. I. Variation in the old field mouse (Peromyscus polionotus). Studies in Genetics IV. Publication 7103. University of Texas Press, Austin, TX, USA.

19. Ayala, F.J., J.R. Powell, M.L. Tracey, C.A. Mourao and S. Perez-Salas. 1972. Enzyme variability in the Drosophila willistoni group. IV. Genetic variation in natural populations of Drosophila willistoni. Genetics 70:113-139.

20. Wright, S. 1978. Evolution and the Genetics of Populations, Vol. 4-Variability Within and Among Natural Populations. University of Chicago Press, Chicago, IL, USA.

21. Hartl, D.L. and A.G. Clark. 1989. Principles of Population Genetics. Sinauer, Sunderland, MA, USA.

22. Selander, R.K. 1970. Behavior and genetic variation in natural populations. Am. Zool. 10:53-66.

23. Swofford, D.L. and R.B. Selander. 1981. BIOSYS-1: A FORTRAN program for the comprehensive analysis of electrophoretic data in population genetics and systematics. J. Hered. 72:281-283.

24. SAS Institute. 1988. SAS ${ }^{\circledR}$ STAT Procedures Guide, Release 6.03. Cary, NC, USA.

25. Diamond, S.A., M.C. Newman, M. Mulvey, P.M. Dixon and D. Martinson. 1989. Allozyme genotype and time to death of mosquitofish, Gambusia affinis (Baird and Girard), during acute exposure to inorganic mercury. Environ. Toxicol. Chem. 8:613-622.

26. Newman, M.C., S.A. Diamond, M. Mulvey and P. Dixon. 1989. Allozyme genotype and time to death of mosquitofish, Gambusia affinis (Baird and Girard), during acute exposure: A comparison of arsenate and inorganic mercury. Aquat. Toxicol. 15:141-156.

27. Heagler, M.G., M.C. Newman, M. Mulvey and P.M. Dixon. 1993. Allozyme genotype in mosquitofish, Gambusia holbrooki, during mercury exposure: Temporal stability, concentration effects and field verification. Environ. Toxicol. Chem. 12:385-395.

28. Lee, C.J., M.C. Newman and M. Mulvey. 1992. Time to death of mosquitofish (Gambusia holbrooki) during acute inorganic mercury exposure: Population structure effects. Arch. Environ. Contam. Toxicol. 22:284-287. 